\title{
JGZ-richtlijn Gezonde slaap en slaapgedrag
}

\author{
M. Beltman · E. Vlasblom
}

Published online: 10 July 2017

(c) Bohn Stafleu van Loghum 2017

Samenvatting In februari 2017 is de JGZ-richtlijn Gezonde slaap en slaapproblemen bij kinderen gepubliceerd. Belangrijk doel van de richtlijn is JGZ-professionals te ondersteunen bij het bevorderen van gezond slaapgedrag en het verminderen van slaapproblemen bij kinderen van 0 tot 18 jaar.

Trefwoorden gezonde slaap · signaleren · interventie

\section{Waarom deze richtlijn?}

Slaap is een normale, periodiek optredende toestand van rust, die gepaard gaat met een verlaging van het bewustzijn, waarbij het lichaam en de geest tot rust komen. De behoefte aan slaap neemt af in de loop van de ontwikkeling. Slaapgedrag van kinderen en ook slaapduur is van veel factoren afhankelijk. Het is daarom lastig te bepalen wat hierin normaal en voldoende is. De grens tussen een slaapprobleem en een slaapstoornis is moeilijk scherp te definiëren. Beter is een spectrum voor te stellen waarbij een gezonde, niet problematische slaap en normaal functioneren overdag aan het ene eind van het spectrum te vinden is en slaapstoornissen aan de andere kant van het spectrum. Ergens daartussenin zijn slaapproblemen te plaatsen die, als zij in ernst, frequentie en/of duur toenemen, over kunnen gaan in een slaapstoornis.

Op de leeftijd van 0 tot 2 jaar komen slaapproblemen vaak voor; ze behoren tot de 'normale' opvoedingsproblemen in deze ontwikkelingsfase [1]. Echter als de problemen in frequentie, duur of intensiteit toenemen, kunnen ze door ouders als ernstig en belemmerend worden ervaren. Prevalentiecijfers van slaap-

\section{Beltman $\cdot$ E. Vlasblom $(\square)$}

TNO, Leiden, Nederland

eline.vlasblom@tno.nl problemen bij peuters en kleuters liggen in internationale studies tussen de $20-30 \%$ [2]. Nederlands onderzoek bij kinderen van 2 tot 14 jaar rapporteert dat ongeveer een kwart van de ouders minstens 1 slaapgerelateerd probleem ervaart [3]. Bij adolescenten ligt de prevalentie van slaapproblemen tussen de 7 en $36 \%$ [4].

Slaapproblemen bij kinderen kunnen niet alleen lastig zijn, ze kunnen ook andere problemen veroorzaken. Slaapproblemen, een slaaptekort en daarbij behorende moeheid overdag kunnen bij kinderen bijvoorbeeld leiden tot emotionele/gedragsproblemen en ongevallen [5], gewichtstoename [6], angst- en depressieklachten, aandachtsproblemen [7], cognitieve prestaties [8, 9] en hyperactiviteit [10]. Bij adolescenten heeft een slaaptekort negatieve gevolgen voor de schoolprestaties en het cognitief functioneren, en zien we meer depressie, angst, gedragsproblemen, risicogedrag, auto-ongelukken, roken, alcohol en drugsgebruik [5, 11]. Uit crosssectionele studies blijkt dat er een associatie is tussen slaaptekort en slechte ervaren gezondheid, gewichtstoename, pijn, verhoogd cardiovasculair en cardiometabool risico, aandachtsproblemen, afzondering, agressie, geweld en suïcidale gedachten. Soms ontstaat er een vicieuze cirkel, slaaptekort leidt tot depressie en depressie en angst zijn sterke voorspellers voor slaapproblemen. Dit geldt ook voor pijnklachten en middelengebruik. Slaapproblemen bij kinderen kunnen ook een negatief effect hebben op de mentale en fysieke gezondheidstoestand van ouders [12].

De JGZ kan adequaat signaleren en behandelen bij slaapproblemen en verwijzen wanneer er mogelijk sprake is van een slaapstoornis. Deze JGZ-richtlijn kan richting en uniformiteit geven aan het handelen van JGZ-hulpverleners. Hierbij worden handvatten gegeven voor voorlichting, preventie en vroege op- 
sporing, symptomen en signalering, ondersteuning en behandeling, en verwijzing en nazorg.

\section{Uitgangsvragen}

De JGZ-richtlijn Gezonde slaap en slaapgedrag [13] is gebaseerd op een knelpuntenanalyse, uitgevoerd door het voormalig Kwaliteitsinstituut voor de Gezondheidszorg CBO en de Argumentenfabriek [14]. De knelpunten zijn vertaald naar de volgende uitgangsvragen, waarop in de richtlijn een antwoord wordt gegeven.

1. Wat is de definitie van slaapproblemen en slaapstoornissen en wat is het verschil hiertussen?

2. Wat is, naar leeftijd en geslacht, normaal en afwijkend slaapgedrag, en wat zijn hierin (sociaal-)culturele verschillen?

3. Wat zijn, naar leeftijd, slaapproblemen en hun oorzaken?

4. Wat zijn risicofactoren en beschermende factoren voor slaapproblemen?

5. Wat is de invloed van alcohol, drugs en energiedrank op slapen?

6. Wat is de invloed van slaapgedrag op gebruik van alcohol, drugs en energiedrank?

7. Welke psychische en fysieke stoornissen kunnen welke slaapproblemen veroorzaken?

8. Welke slaapproblemen kunnen welke psychische en fysieke stoornissen (mede) veroorzaken?

9. Wat is het belang van goede slaap voor ouder en kind en hoe beïnvloedt het de ontwikkeling van het kind?

10. Wanneer moeten JGZ-werkers acuut ingrijpen bij slaapproblemen voor de veiligheid van het kind?

11. Wat is het effect van geneesmiddelengebruik door het kind (waaronder slaap- en wekmiddelen) op slaapgedrag?

12. Wat zijn, naar leeftijd, valide instrumenten voor de JGZ voor het signaleren van slaapproblemen?

13. Hoe kunnen JGZ-werkers oorzaken voor slaapproblemen bepalen?

14. Welke samenwerkingsafspraken moet de JGZ maken met welke partijen over het signaleren van slaapproblemen?

15. Wat zijn, naar leeftijd, bewezen effectieve methodes om slaapproblemen te voorkomen?

16. Hoe kunnen JGZ-werkers ouders preventief adviseren om normaal slaapgedrag te stimuleren?

17. Wat zijn, naar leeftijd en naar slaapprobleem, bewezen effectieve interventies die JGZ-werkers kunnen toepassen om slaapproblemen te verminderen?

18. In welke volgorde kunnen JGZ-werkers, voor verschillende slaapproblemen, interventies toepassen?

19. In welke situatie moeten JGZ-werkers naar wie verwijzen en welke interventies zijn daar beschikbaar?
20. Wie kunnen JGZ-werkers in welke situatie consulteren om te overleggen over een kind?

\section{Opbouw van de richtlijn en aanbevelingen}

De richtlijn is opgedeeld in de volgende 7 thema's: gezonde slaap, slaapproblemen, factoren die samenhangen met slaap, preventie, signalering en beoordeling, interventie en begeleiding, en samenwerken en doorverwijzen.

Om slaapproblemen te voorkomen worden ouders en jeugdigen tijdens alle contactmomenten voorgelicht over het belang van voldoende slaap en een gezonde slaaphygiëne (zie box).

Geadviseerd wordt om aan alle ouders en jongeren de vraag te stellen of ze zich wel eens zorgen maken over het slapen (van hun kind). Daarbij is het verstandig na te gaan of de ouders de situatie nog aan kunnen. Het borgen van de veiligheid van het kind is hierin essentieel. Indien ouders of de jongere zelf aangeven dat er sprake is van een slaapprobleem, is het onder meer van belang te vragen naar de slaapduur, het slaapgedrag, slaperigheid overdag en ongebruikelijke gedragingen. Om na te gaan of er een medische oorzaak voor het slaapprobleem kan zijn, moet de jeugdige door een jeugdarts onderzocht worden. Indien er na gedegen anamnese, lichamelijk en psychosociaal onderzoek geen aanwijzingen zijn voor

\section{Box Preventieve adviezen}

- Een vast slaapschema: bedtijd en tijd om te ontwaken zouden iedere dag ongeveer hetzelfde moeten zijn (na de leeftijd van 6 maanden).

- Slaapritueel: houd een vast slaapritueel aan van ongeveer 20-30 minuten. De routine dient te bestaan uit rustige activiteiten. Specifiek bij baby's: 'slaperig maar nog wakker' in bed leggen.

- Slaapkamer: comfortabel, rustig en donker, $16-18^{\circ} \mathrm{C}$. Gebruik het bed niet voor andere activiteiten dan slapen.

- Vermijd zware maaltijden in de 2 uur voor bedtijd.

- Vermijd stimulerende middelen zoals cafeïne (in ieder geval niet in de 3-4 uur voor het slapen gaan), alcohol, roken en blowen.

- Vermijd stimulerende avondactiviteiten in het uur voor het naar bed gaan.

- Vermijd schermgebruik voor het slapen gaan.

- Dutjes bij oudere kinderen en tieners: het overdag slapen dient in de regel vermeden te worden, omdat slaap overdag bij kan dragen aan lastiger inslapen en doorslapen gedurende de nacht.

- Beweging: regelmatig naar buiten en inspanning gedurende de dag zorgt voor betere slaap in de nacht.

- Zonlicht: blootstelling aan zonlicht helpt om een normaal slaap-waakritme te behouden. 
onderliggende pathologie, wordt gestart met een interventie of, indien nodig, doorverwezen.

\section{Praktijktest en randvoorwaarden voor implementatie}

Tussen eind 2015 en begin 2016 vond de praktijktest plaats. Na instructie over de richtlijn werkten 32 JGZ-medewerkers vanuit vier organisaties een aantal maanden met de richtlijn. Na afloop van de praktijktest werd hen gevraagd een vragenlijst in te vullen en mee te doen met een online focusgroep. Daarnaast werden jongeren en ouders gevraagd mee te doen met een online focusgroep.

De richtlijn bleek voor veel JGZ-professionals die deelnamen aan de praktijktest geen grote veranderingen ten opzichte van de huidige werkwijze te bevatten. JGZ-medewerkers vinden de richtlijn niettemin nuttig. Op basis van de vragenlijst en focusgroepen werden knelpunten en verbetersuggesties voor de inhoud van de richtlijn geïnventariseerd en werd de richtlijn op de volgende punten aangepast:

- Er is een bijlage opgenomen over sensitief opvoeden en een kind dat niet slaapt.

- De beschrijving van de interventies is uitgebreid en er is toegevoegd wat na het inzetten van een interventie zou moeten gebeuren aan opvolging.

- Er is een interventie toegevoegd voor doorslaapproblemen bij naar schoolgaande kinderen ("de bedtijd pas").

- De dagboekjes worden in de richtlijn aanbevolen, maar niet verplicht.

- De aanbeveling over de begeleiding bij melatonine is aangepast.

Een belangrijke voorwaarde voor landelijke implementatie van deze richtlijn is dat enkele medewerkers per organisatie geschoold zijn in het toepassen van de beschreven interventies. De beschrijving van de interventies in de richtlijn kan een uitgebreide scholing niet vervangen. Door JGZ-medewerkers wordt "tijd" genoemd als belangrijke voorwaarde om de richtlijn uit te voeren zoals bedoeld. Daarnaast is het belangrijk per organisatie en per regio na te gaan hoe kan worden samengewerkt met andere zorgprofessionals bij slaapproblemen, bijvoorbeeld bij het signaleren en verwijzen.

\section{Meer informatie?}

De JGZ-richtlijn Gezonde slaap en slaapgedrag is ontwikkeld door TNO. De richtlijn is gefinancierd door ZonMw. Voor de volledige tekst en de ondersteunende producten zoals de samenvattingskaart en anamnese vragenlijsten, zie: www.jgzrichtlijnen.nl. Hier vindt $u$ ook gegevens over de auteurs en de totstandkoming van de richtlijn.

\section{Literatuur}

1. Yperen TV van, Stam PT. Opvoeden versterken. Den Haag: VNG;2010.

2. Mindell JA, Kuhn B, Lewin DS, Meltzer LJ, Sadeh A. Behavioral treatment of bedtime problems and night wakings in infants and young children -an American academy of sleep medicine review. Sleep. 2006;29:1263-76.

3. Litsenburg RR van, Waumans RC, Berg G van den, Gemke RJ. Sleep habits and sleep disturbances in dutch children: A population-based study. Eur J Pediatr. 2010;169:1009-15.

4. Gradisar M, Gardner G, Dohnt H. Recent worldwide sleep patterns and problems during adolescence: A review and meta-analysis of age, region, and sleep. Sleep Med. 2011;12:110-8.

5. Dewald JF, Meijer AM, Oort FJ, Kerkhof GA, Bögels SM. The influence of sleep quality, sleep duration and sleepiness on school performance in children and adolescents: a metanalytic review. Sleep Med Rev. 2010;14:179-89.

6. Monasta L, Batty GD, Cattaneo A, et al. Early-life determinants of overweight and obesity: a review of systematic reviews. Obes Rev. 2010;11:695-708.

7. Gregory AM, Ende J van der, Willis TA, Verhulst FC. Parentreported sleep problems during development and selfreported anxiety/depression, attention problems, and aggressive behavior later in life. Arch Pediatr Adolesc Med. 2008;162:330-5.

8. Astill RG, Heijden KB van der, Ijzendoorn MH van, Someren EJvan. Sleep, cognition, and behavioral problems in schoolage children: A century of research meta-analyzed. Psychol Bull. 2012;138:1109-38.

9. Kheirandish L, Gozal D. Neurocognitive dysfunction in children with sleep disorders. Dev Sci. 2006;9:388-99.

10. Owens J, Gruber R, Brown T, etal. Future research directions in sleep and ADHD: report of a consensus working group. JAtten Disord. 2013;17:550-64.

11. Bruin EJ de, Run C van, Staaks J, Meijer AM. Effects of sleep manipulation on cognitive functioning of adolescents: a systematic review. Sleep Med Rev. 2016;32:45-57.

12. Martin J, Hiscock H, Hardy P, Davey B, Wake M. Adverse associations of infant and child sleep problems and parent health: an australian population study. Pediatrics. 2007;119:947-55.

13. Vlasblom E, Sleuwen BE van, L'Hoir MP, Beltman M. JGZRichtlijn: Gezonde slaap en slaapproblemen bij kinderen. Leiden/Utrecht: TNO/NCJ;2017.

14. De Argumentenfabriek, CBO. Knelpuntenanalyse Jeugdgezondheidszorg. Utrecht: CBO;2015.

M. Beltman, teamleider Zorg voor Jeugd en richtlijnontwikkelaar.

E. Vlasblom, wetenschappelijk medewerker en richtlijnontwikkelaar. 